\title{
Immunization Coverage in South Bačka County of Vojvodina, Serbia
}

\author{
Vladimir Petrović*and Zorica Šeguljev \\ Institute of Public Health of Vojvodina, Center for Disease Control and Prevention, Novi Sad, Serbia
}

\begin{abstract}
Introduction: Immunization coverage is a key measure of immunization system performance.

Objective: was to assess immunization coverage by combination series of vaccines 3:3 ( 3 doses of both DTP/ DTaP and OPV/IPV vaccines) and 4:4:1 (4 doses of both DTP/DTaP and OPV/IPV and one dose of MMR vaccine) in a representative sample of children in South Backa County. Up-to-date (UTD) and age-appropriate criteria of immunization coverage were applied at 6, 12 and 24 months of age.
\end{abstract}

Methods: Modified birth certificates follow-back method was used in order to obtain immunization records of 2058 children and to measure UTD and age-appropriate immunization coverage.

Results: UTD coverage with combination series $3: 3$ was $60.1 \%$ and $94.0 \%$ at 6 and 12 months of age, respectively. At 24 months of age, $85.8 \%$ of children were fully immunized with combination series $4: 4: 1$. Ageappropriate immunization coverage of $94.4 \%$ was reached.

Conclusion: Effective protection against all targetted diseases has been reached by 12 months of age. High level of age-appropriate immunization coverage shows that the risk of vaccine preventable diseases is small between the $3^{\text {rd }}$ and $5^{\text {th }}$ year of life and warrants low risk of vaccine preventable diseases. Though achieved with some delay, high level of age-appropriate immunization coverage warrants low risk of vaccine preventable diseases at preschool age in the studied population. Combination series should be used for measuring immunization coverage because it provides better understanding of the immunization process to all stakeholders.

Keywords: Immunization; Immunization assessments; Vaccines\

\section{Introduction}

Immunization coverage is a key measure of immunization system performance [1]. As stated by the World Health Organization [2], information on immunization coverage is used for a variety of purposes: to monitor the performance of immunization services at local, national and international levels; to guide polio eradication, measles control, and neonatal tetanus elimination; to identify areas of weak system performance that may require extra resources and focused attention; and as one's consideration when deciding whether to introduce a new vaccine.

In order to obtain complete data on immunization system performance in USA, immunization coverage is measured by National Immunization Survey (NIS) conducted by the Centers for Disease Control and Prevention (CDC) since 1994 [3]. Two most commonly used immunization status measures in USA are "age-appropriate" and "up-to-date" (UTD). Age-appropriate are applied to a population or cohort of children that varies in age, and the measure indicates the proportion of children who received adequate number of vaccines for their actual age. UTD immunization coverage generally indicates the proportion of children in a population with adequate immunization status at a certain age threshold or age range [4-6].

Age appropriate and UTD immunization coverage using combination series at any age in South Bačka County were never measured. We expected that the UTD immunization coverage at 6 months of age would be much lower than $95 \%$ and that at 12 and 24 months of age there would be high and satisfactory UTD coverage.

\section{Objective}

Objectives of this research were to assess:

- age-appropriate immunization coverage by combination of vaccine series 4:4:1 in representative sample of children in South Backa County,

- UTD combination series immunization coverage at 6,12 and 24 months of age in the same sample of children of the target population in South Backa County.

\section{Methods}

Immunization in Serbia is mandatory and regulated by the law. Each child must be immunized according to the immunization schedule set by the National Immunization Program. Parents are mandated to bring their children to the vaccination station when they receive official call from the elected physician.

Research was conducted in South Bačka County in Vojvodina, the northern province of Serbia. There are 12 municipalities in the county and there is a Health Center in each municipality. Health Center is organized as a number of health stations which are also vaccination stations. Each vaccination station is responsible for the immunization of children living in the area covered by the station. There are 82 vaccination stations in the county. Private practice also conducts immunization according to explicit demands of the parents. There

*Corresponding author: Vladimir Petrović, Institute of Public Health of Vojvodina Center for Disease Control and Prevention, Futoška 121, 21000 Novi Sad, Serbia, Tel: +381214897886; Fax:+381216613989; E-mail: vladimir.petrovic@izjzv.org.rs

Received December 15, 2011; Accepted January 23, 2012; Published January 27, 2012

Citation: Petrović V, Šeguljev Z (2012) Immunization Coverage in South Bačka County of Vojvodina, Serbia. J Vaccines Vaccin 3:125. doi:10.4172/2157. 7560.1000125

Copyright: $\odot 2012$ Petrović V, et al. This is an open-access article distributed under the terms of the Creative Commons Attribution License, which permits unrestricted use, distribution, and reproduction in any medium, provided the original author and source are credited. 
are 8 private practitioners conducting immunization in South Bačka County.

There were 95955 children up to 14 years of age in South Bačka County according to the 2002 census [7] and the number of children was stable throughout the years. In the period from January 1, 2001 to December 31, 2005, total of 26719 children were born in and had residency in South Bačka County according to the list of birth certificates obtained from the local birth certificate registries. Birth certificates follow-back method was modified so that children migrating into the county were not included in the reasearch due to the fact that their immunization started elsewhere [8]. Research was conducted on sistematic sample of children, stratified by the calendar year of birth. All live born children were listed and then sorted by the date of birth. In each birth cohort the first participant was chosen randomly among the first 12 listed children. After that every $12^{\text {th }}$ child was selected in the sample. Total of 2226 children were sampled comprising $8,3 \%$ of children from each birth cohort.. Exclusion criteria were: emigration from the South Backa County before the age of 24 months, immigration during the first two years of life, child's death or parrental refusal to provide written consent for the use of child's immunization records. Migrants were not included in the study because immunization of these children was not fully conducted by health care providers from South Bačka County. Exclusion of migrant children does not interfere and affect the sample representativeness for the observed age group as a whole because the idea was to evaluate a immunization system performance in South Backa County.

Research started at the end of March 2006. Lists of children for each vaccination station were made acording to the place of residency and the date of birth. Lists of children and forms for informed consent of parents were sent to the physicians in vaccination stations. After a parent signed informed consent, immunization records were scrutinized. It took us 13 months to visit all the parents and after that to track all scattered immunization records because immunization of some participants was conducted by different providers. The study was conducted in 78 vaccination stations of 12 Health Centers in the county and in 3 private practices where records of selected children were located. Field work ended on May 10, 2007 and this point was used to measure the age appropriate immunization coverage in all selected children in order to investigate whether missed doses of the combination series were administered after the $2^{\text {nd }}$ year of life and to check whether the risk of vaccine preventable diseases was decreasing during the period from $3^{\text {rd }}$ to $5^{\text {th }}$ year of age.

By the end of the study immunization records of 2058 participants ( $92.5 \%$ of the sample and $7.7 \%$ of the target population) were obtained. Birth cohort 2005 had the highest (94.0\%), and birth cohort 2003 the lowest (90.6\%) compliance rate. Drop-out rate of 7.5\% comprised 168 originally selected participants: 17 of them died, 75 moved away and for 76 parents refused to give written consent.

Provider validation was used as a proof of immunization and dates of application of each dose of vaccine for each child were obtained. In order to validate data, health care providers checked children's medical charts, personal medical cards and immunization charts.

We examined immunization status against diphtheria, tetanus and pertussis with DTP or DTaP vaccine, against polio with oral (OPV) or inactivated polio vaccine (IPV) and against measles, mumps and rubella with MMR vaccine. Research did not include immunization against hepatitis $\mathrm{B}$ and Haemophilus influenzae type $\mathrm{b}$ because they were introduced into the national immunization schedule in mid-2005.
We used two different combination series of vaccines in order to assess the UTD immunization coverage:

a Combination series 3:3 at 6 and 12 months of age. It comprised series of 3 doses of DTP/DTaP vaccines and 3 doses of OPV/ IPV vaccines.

b Combination series 4:4:1 at 24 months of age and age appropriate immunization coverage. It comprised series of 4 doses of DTP/DTaP vaccines, 4 doses of OPV/IPV vaccines and one dose of measles-mumps-rubella (MMR) vaccine.

A child who had the combination series $3: 3$ or $4: 4: 1$ entered in his/ her immunization record by 6,12 , and 24 months of age or by the end of the study was considered completely immunized. If any of the dates of vaccine administration was missing in the immunization record by the same cut-off points in time, the child was considered incompletely immunized, and if all the fields remained blank, he/she was considered unimmunized. Age-appropriate immunization coverage was calculated for the total sample of children. UTD immunization coverage by 6,12 and 24 months of age was calculated for the total sample of children and for the birth cohorts in the period from 2001 to 2005 .

After data colection and validation, data base was formed in Microsoft Excel 2003 and statistical analyses conducted using the software package STATISTICA 8.0.

\section{Results}

\section{UTD immunization coverage by 6 months of age}

When UTD was used as the criterion for immunization coverage, $60.1 \%$ of children were covered with combination series $3: 3$ by 6 months of age, while $35.4 \%$ remained incompletely immunized and $4.5 \%$ unimmunized (Figure 1). UTD complete immunization coverage by 6 months of age ranged from $57.2 \%$ in the group of children born in 2001 to $63.6 \%$ in the 2003 cohort (Table 1). As for incompletely immunized children, the percentage varied from $32.4 \%$ in 2003 to $39.0 \%$ in 2002 , and for unimmunized children the extreme values were $7.1 \%$ in 2001 and $3.5 \%$ in 2002.

\section{UTD immunization coverage by 12 months of age}

By 12 months of age $94.0 \%$ of children were covered with combination series $3: 3$. At that point in time, $2.9 \%$ of children remained incompletely immunized and $3.1 \%$ unimmunized (Figure 1).

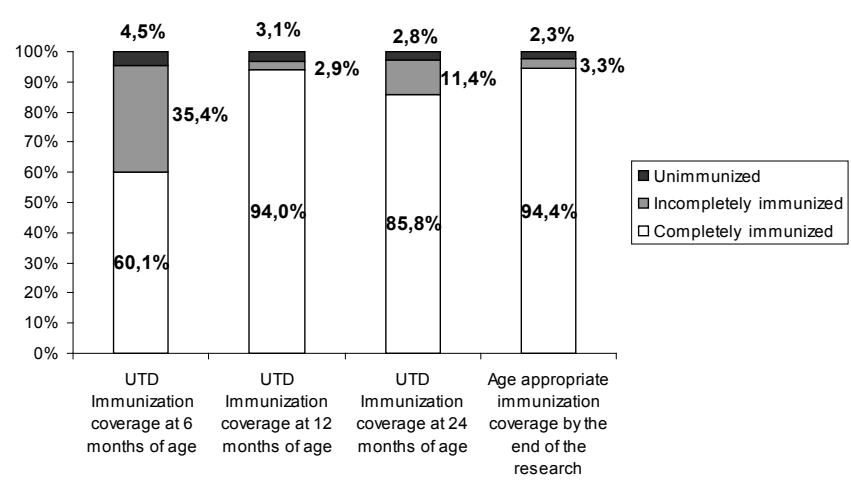

Figure 1: Age appropriate and UTD immunization coverage in South Bačka County in total sample of children born from 2001 to2005. 
UTD complete immunization coverage with combination series $3: 3$ by 12 months of age ranged from $91.9 \%$ in the 2001 cohort to $95.5 \%$ in the 2003 cohort. Thus, either safe or close to safe level of complete coverage was maintained throughout the period. Percentage of incompletely immunized children by 12 months of age ranged from $1.2 \%$ in the 2003 cohort to $4.2 \%$ in the 2005 cohort, while the percentage of unimmunized children was in the bounds from $5.2 \%$ (2001) to $2.1 \%$ (2004) (Table 2).

\section{UTD immunization coverage by 24 months of age}

By 24 months of age complete UTD immunization coverage with combination series $4: 4: 1$ was $85.8 \%$, while $11.4 \%$ of children remained incompletely immunized and $2.8 \%$ unimmunized.

Complete UTD immunization coverage with combination series 4:4:1 by 24 months of age ranged from $84.0 \%$ in the 2001 cohort to $87.6 \%$ in the 2003 cohort (Table 3). Percentage of incompletely immunized children ranged from $9.9 \%$ (2003) to $13.4 \%$ (2004), while the values for unimmunized children varied from $4.7 \%$ (2001) to $1.7 \%$ (2004).

\section{Age appropriate immunization coverage}

When immunization coverage was measured according to the actual age of children, regardless of their age when the vaccines were administered, $94.4 \%$ children were protected with combination series $4: 4: 1,3.3 \%$ of children remained unimmunized and $2.3 \%$ of them incompletely immunized with combination series 4:4:1. High levels of age appropriate immunization coverage show that missed doses form the combination series 4:4:1 have been administrered after the $24^{\text {th }}$ month of life (Figure 1).

\section{Discussion}

In Serbia, as in most European countries, administrative method is used for measuring immunization coverage. Administrative coverage data" are the number of doses administered to the target population or number of immunized individuals in a target population within one calendar year. In order to estimate the proportion of immunization coverage, this number is divided by the total estimated number of people in the target population. Target population groups vary from country to country and depend on the national immunization schedule. The coverage estimates calculated using the administrative method can be biased due to inaccurate numerators or denominators [1]. Administrative immunization coverage in South Bačka Region in the period after 2001 has been above 95\% and the risk of vaccine preventable communicable diseases was assessed as low [9].

The primary disadvantage of a set of individual vaccine measures is the confusion resulting from too much information. Coverage rates of generally accepted vaccines are closely correlated, and reporting many similar numbers measuring similar processes may confuse the consumer of information. Combination measures, however, have certain advantages, primarily the convenience and simplicity of a single-number interpretation of vaccination coverage that is familiar to researchers, providers, non-health care professionals, and policymakers [10]. Use of the $4^{\text {th }}$ dose of DTaP vaccine for measurement of immunization coverage is a possible option to determine percentage of completely immunized children. However, it usually shows lower percentages of incompletely immunized and higher percentages of unimmunized children because other vaccines that the child receives are neglected. All that leads to distorted impression of the protection of population against all vaccine preventable diseases [11].

\begin{tabular}{|c|c|c|c|c|c|c|c|c|}
\hline \multirow{2}{*}{ YEAR OF BIRTH } & \multicolumn{2}{|c|}{ COMPLETELY IMMUNIZED } & \multicolumn{2}{|c|}{ INCOMPLETELY IMMUNIZED } & \multicolumn{2}{|l|}{ UNIMMUNIZED } & \multicolumn{2}{|l|}{ TOTAL } \\
\hline & Number of children & $\%$ & Number of children & $\%$ & Number of children & $\%$ & Number of children & $\%$ \\
\hline 2001 & 233 & $57.2 \%$ & 145 & $35.6 \%$ & 29 & $7.1 \%$ & 407 & $100.0 \%$ \\
\hline 2002 & 230 & $57.5 \%$ & 156 & $39.0 \%$ & 14 & $3.5 \%$ & 400 & $100.0 \%$ \\
\hline 2003 & 257 & $63.6 \%$ & 131 & $32.4 \%$ & 16 & $4.0 \%$ & 404 & $100.0 \%$ \\
\hline 2004 & 264 & $62.6 \%$ & 142 & $33.6 \%$ & 16 & $3.8 \%$ & 422 & $100.0 \%$ \\
\hline 2005 & 253 & $59.5 \%$ & 154 & $36.2 \%$ & 18 & $4.2 \%$ & 425 & $100.0 \%$ \\
\hline TOTAL & 1237 & $60.1 \%$ & 728 & $35.4 \%$ & 93 & $4.5 \%$ & 2058 & $100.0 \%$ \\
\hline
\end{tabular}

Table 1: UTD immunization coverage with combination series $3: 3$ by 6 months of age in children born in $2001-2005$.

\begin{tabular}{|c|c|c|c|c|c|c|c|c|}
\hline \multirow{2}{*}{ YEAR OF BIRTH } & \multicolumn{2}{|c|}{ COMPLETELY IMMUNIZED } & \multicolumn{2}{|c|}{ INCOMPLETELY IMMUNIZED } & \multicolumn{2}{|l|}{ UNIMMUNIZED } & \multicolumn{2}{|l|}{ TOTAL } \\
\hline & Number of children & $\%$ & Number of children & $\%$ & Number of children & $\%$ & Number of children & $\%$ \\
\hline 2001 & 374 & $91.9 \%$ & 12 & $2.9 \%$ & 21 & $5.2 \%$ & 407 & $100.0 \%$ \\
\hline 2002 & 378 & $94.5 \%$ & 12 & $3.0 \%$ & 10 & $2.5 \%$ & 400 & $100.0 \%$ \\
\hline 2003 & 386 & $95.5 \%$ & 5 & $1.2 \%$ & 13 & $3.2 \%$ & 404 & $100.0 \%$ \\
\hline 2004 & 401 & $95.0 \%$ & 12 & $2.8 \%$ & 9 & $2.1 \%$ & 422 & $100.0 \%$ \\
\hline 2005 & 397 & $93.4 \%$ & 18 & $4.2 \%$ & 10 & $2.4 \%$ & 425 & $100.0 \%$ \\
\hline TOTAL & 1936 & $94.0 \%$ & 59 & $2.9 \%$ & 63 & $3.1 \%$ & 2058 & $100.0 \%$ \\
\hline
\end{tabular}

Table 2: UTD immunization coverage with combination series 3:3 by 12 months of age in children born in $2001-2005$.

\begin{tabular}{|c|c|c|c|c|c|c|c|c|}
\hline \multirow{2}{*}{ YEAR OF BIRTH } & \multicolumn{2}{|c|}{ COMPLETELY IMMUNIZED } & \multicolumn{2}{|c|}{ INCOMPLETELY IMMUNIZED } & \multicolumn{2}{|l|}{ UNIMMUNIZED } & \multicolumn{2}{|l|}{ TOTAL } \\
\hline & Number of children & $\%$ & Number of children & $\%$ & Number of children & $\%$ & Number of children & $\%$ \\
\hline 2001 & 342 & $84.0 \%$ & 46 & $11.3 \%$ & 19 & $4.7 \%$ & 407 & $100.0 \%$ \\
\hline 2002 & 344 & $86.0 \%$ & 46 & $11.5 \%$ & 10 & $2.5 \%$ & 400 & $100.0 \%$ \\
\hline 2003 & 354 & $87.6 \%$ & 40 & $9.9 \%$ & 10 & $2.5 \%$ & 404 & $100.0 \%$ \\
\hline 2004 & 360 & $85.3 \%$ & 55 & $13.0 \%$ & 7 & $1.7 \%$ & 422 & $100.0 \%$ \\
\hline 2005 & 366 & $86.1 \%$ & 49 & $11.5 \%$ & 10 & $2.4 \%$ & 425 & $100.0 \%$ \\
\hline TOTAL & 1766 & $85.8 \%$ & 236 & $11.4 \%$ & 56 & $2.8 \%$ & 2058 & $100.0 \%$ \\
\hline
\end{tabular}

Table 3: UTD immunization coverage with combination series $4: 4: 1$ by 24 months of age in children born in $2001-2005$. 
Birth certificates follow-back method based on random sampling was used in Oregon, Georgia and Puerto Rico [8]. We used sistematic random sample and selection of every $12^{\text {th }}$ born child in the observed period enabled that children born during the whole year be represented and made possible to look into continuous immunization performance in South Backka County from 2001 to 2005. This kind of approach without computerized immunization registry demands significant effort to track all the immunization records of a child because archives of health care providers and parental adresses of residence are needed. It took us 13 months to find all the data and to measure immunization coverage with combination series of vaccines. Methodology is especially demanding in areas where the migration of families is high [12-14].

Low immunization coverage in preschool children exposes them to the risk of vaccine preventable diseases and complications and therefore coverage should be constantly monitored [15]. Current methodology of immunization coverage measurement in preschool children in the USA, either if measured by the coverage with combination series at 24 months of age or age-appropriately is insufficient because the risk of vaccine preventable communicable diseases is not evaluated within the first 24 months of age and the time of immunization commencement and age at which vaccines are administered are not considered [16]. Also, when administrative method for immunization coverage measurement is used, data at the national level are not sufficient enough to detect subpopulations with low immunization coverage, combination series UTD coverage is lower for about $15 \%$ in comparison with immunization coverage with individual vaccines and there is no posibility to evaulate percentage of incompletely immunized and unimmunized children [17-19]. Depending on the observed combinations of series of vaccines in the period 2001-2005, around $70-78 \%$ of children aged $19-35$ months in USA were completely immunized and about one quarter of children remained incompletely immunized or unimmunized $[20,21]$. These children are at greater risk of disease and represent potential reservoirs of infection within their communities $[22,23]$.

We have observed significantly higher age-appropriate immunization coverage than in studies from USA, but the combination series in Serbia is much simpler. Significant differencies in UTD immunization coverage were noticed when measured at 6,12 and 24 months of age. Coverage is considerably under the safe level when assessed at 6 months of age compared to coverage at 12 months of age and during the $2^{\text {nd }}$ year of life a significant coverage reduction occurs. Factors causing these results might have been scattered immunization records, true medical contraindications and missed opportunities. Special analysis within this sample is needed to provide us with an answer. The percentage of incompletely immunized children reflects changes in coverage but in the opposite direction. It is encouraging that, although incompletely immunized, these children were registered within the health care system during the first 6 months of life. Unimmunized children are represented in low percentage at 6,12 and 24 months of age, and the percentage is decreasing.

Our results additionally confirm the fact that the health care system in South Bačka and, by analogy, in Vojvodina as a whole, achieved significant successes in controlling vaccine preventable diseases through mandatory immunization system thanks to the increase and maintenance of high immunization coverage. However, through the administrative method of immunization coverage measurement we were not able to evaluate more precisely percentages of children at risk of any vaccine preventable disease.

\section{Conclusion}

Effective protection against all targetted diseases has been reached by 12 months of age. Though achieved with some delay, high level of age-appropriate immunization coverage warrants low risk of vaccine preventable diseases at preschool age in the studied population.

Combination series should be used for immunization coverage measuring in order to evaluate immunization system performance because it provides better understanding of the immunization process to all stakeholders.

Electronic immunization registry would be necessary prerequisite for tracking, scheduling and measuring outcome on an ongoing basis.

\section{References}

1. World Health Organization. Immunization coverage. Department for Vaccines and Biologicals, Immunization, Surveillance and Monitoring System.

2. World Health Organization. WHO \& UNICEF estimates of national immunization coverage, 1980-2004. Department for Vaccines and Biologicals, Immunization, Surveillance and Monitoring System.

3. Luman ET, McCauley MM, Stokley S, Chu SY, Pickering LK (2002) Timeliness of Childhood Immunizations. Pediatrics 110: 935-939.

4. Darden PM, Taylor JA (1998) Assessing immunization rates in office practice Pediatr Ann 27: 411-416.

5. Darden PM, Taylor JA, Slora EJ, Hasemeier CM, Asmussen L, et al. (1996) Methodological issues in determining rates of childhood immunization in office practice. A study from pediatric research in office settings (PROS). Arch Pediatr Adolesc Med 150: 1027-1031.

6. Ross A, Kennedy A, Holt E, Guyer B, Hou W (1998) Initiating the first DTP vaccination age appropriately: a model for understanding vaccination coverage. Pediatrics 101: 970-974.

7. Republički zavod za statistiku Srbije (2003) STANOVNIŠTVO : popis stanovništva,domaćinstava i stanova u 2002. 2, Pol i starost : podaci po naseljima. Beograd.

8. Salmon DA, Smith PJ, Navar AM, Pan WKY, Omer SB, et al. (2006) Measuring Immunization Coverage among Preschool Children: Past, Present, and Future Opportunities. Epidemiol Rev 28: 27-40.

9. Šeguljev Z, Petrović V, Ćosić G, Durić P, Petrović M, et al. (2007) Results of the immunization program performance in Vojvodina. Med Rew 60: 553-557.

10. Rodewald L, Maes E, Stevenson J, Lyons B, Stokley S, et al. (1999) Immunization Performance Measurement in a Changing Immunization Environment. Pediatrics 103: 889-897.

11. Rickert DL, Shefer AM, Rodewald LE, McCauley MM (2003) Counting the shots: a model for immunization screening and referral in nonmedical settings. Pediatrics 111: 1297-1302

12. Marshall GS, Happe LE, Lunacsek OE, Szymanski MD, Woods CR, et al (2007) Use of combination vaccines is associated with improved coverage rates. Pediatr Inf Dis 26: 496-500.

13. Guyer B, Hughart N (1994) Increasing childhood immunization coverage by improving the effectiveness of primary health care systems for children. Arch Pediatr Adolesc Med 148: 901-948.

14. Centers for Disease Control and Prevention, Division of Reproductive Health (2006) Pregnancy Risk Assessment Monitoring System (PRAMS): Methodology.

15. Renfrew BL, Kempe A, Lowery NE, Chandramouli V, Steiner JF, et al. (2001) The impact of immunization record aggregation on up-to-date ratesimplications for immunization registries in rural areas. J Rural Health 17: 122126.

16. Luman ET, Barker LE, Shaw KM, McCauley MM, Buehler JW, et al. (2005) Timeliness of childhood vaccinations in the United States: days under vaccinated and number of vaccines delayed. JAMA 293: 104-111.

17. Bentsi-Enchill A, Litt M (1999) Vaccine-Prventable diseases. In: Measuring Up: A Health Surveillance Update on Canadian Children and Youth. Eds ID Rusen, CMcCourt. Public Health Agency of Canada. 
Citation: Petrović V, Šeguljev Z (2012) Immunization Coverage in South Bačka County of Vojvodina, Serbia. J Vaccines Vaccin 3:125. doi:10.4172/21577560.1000125

Page 5 of 8

18. Salmaso S, Rota MC, Ciofi Degli Atti ML, Tozzi AE, Kreidl P (1999) Infant immunization coverage in Italy: estimates by simultaneous EPI cluster surveys of regions. Bulletin of the World Health Organization 77: 843- 851

19. Mell LK, Ogren DS, Davis RL, Mulloly JP, Black SB, et al. (2005) Compliance with national immunization guidelines for children younger than 2 years, 19961999. Pediatrics 1150: 461-467.

20. Centers for Disease Control and Prevention (2002) National, state, and urban area vaccination coverage levels among children aged 19-35 months-United States, 2001. MMWR 51: 664-666.
21. Levine RS, Briggs NC, Husaini BA, Foster I, Hull PC, et al. (2005) HEDIS prevention performance indicators, prevention quality assessment and Healthy People 2010. J Health Care Poor Underserved 16: 64-82.

22. Feikin DR, Lezotte DC, Hamman RF, Salmon DA, Chen RT, et al. (2000) Individual and community risks of measles and pertussis associated with personal exemptions to immunization. JAMA 284: 3145-3150.

23. Omer SB, Pan WK, Halsey NA, Stokley S, Moulton LH, et al. (2006) Nonmedical exemptions to school immunization requirements: secular trends and association of state policies with pertussis incidence. JAMA, 296: 17571763. 